\title{
A converging subset of soil bacterial taxa is permissive to the IncP-1 plasmid pKJK5 across a range of soil copper contamination
}

Song, Jianxiao; Klümper, Uli; Riber, Leise; Dechesne, Arnaud; Smets, Barth F.; Sørensen, Søren J; Brandt, Kristian Koefoed

\author{
Published in: \\ FEMS Microbiology Ecology
}

Link to article, DOI:

10.1093/femsec/fiaa200

Publication date:

2020

Document Version

Peer reviewed version

Link back to DTU Orbit

Citation (APA):

Song, J., Klümper, U., Riber, L., Dechesne, A., Smets, B. F., Sørensen, S. J., \& Brandt, K. K. (2020). A converging subset of soil bacterial taxa is permissive to the IncP-1 plasmid pKJK5 across a range of soil copper contamination. FEMS Microbiology Ecology, 96(11), [fiaa200]. https://doi.org/10.1093/femsec/fiaa200

\section{General rights}

Copyright and moral rights for the publications made accessible in the public portal are retained by the authors and/or other copyright owners and it is a condition of accessing publications that users recognise and abide by the legal requirements associated with these rights.

- Users may download and print one copy of any publication from the public portal for the purpose of private study or research.

- You may not further distribute the material or use it for any profit-making activity or commercial gain

- You may freely distribute the URL identifying the publication in the public portal 


\section{A converging subset of soil bacterial taxa is permissive to the IncP-1 plasmid pKJK5 across a range of soil copper contamination}

Jianxiao Song $^{\text {a,b,c }}$, Uli Klümper ${ }^{\text {d,e }}$, Leise Riber ${ }^{\text {b,c }}$, Arnaud Dechesne ${ }^{\mathrm{f}}$, Barth F Smets ${ }^{\mathrm{f}}$, Søren J Sørensen ${ }^{\mathrm{c}^{*}}$, Kristian K Brandt ${ }^{\mathrm{b}^{*}}$

${ }^{a}$ School of Ecology and Environment, Northwestern Polytechnical University, 1 Dongxiang Road, Chang'an District, Xi'an Shaanxi,710129, P.R.China

${ }^{\mathrm{b}}$ Section for Microbial Ecology and Biotechnology, Department of Plant and Environmental Sciences, University of Copenhagen, Thorvaldsensvej 40, 1871 Frederiksberg C, Denmark

${ }^{c}$ Section of Microbiology, Department of Biology, University of Copenhagen,

Universitetsparken 15, Building 1, 2100 Copenhagen, Denmark

d Institute for Hydrobiology, Technische Universität Dresden, Dresden 01217, Germany

${ }^{\mathrm{e}}$ Environment and Sustainability Institute, Medical School, University of Exeter, Penryn Campus, Cornwall, TR10 9FE, UK

${ }^{\mathrm{f}}$ Department of Environmental Engineering, Technical University of Denmark, Miljøvej Building 115, 2800 Kgs. Lyngby, Denmark

* Corresponding author:

Kristian K Brandt: kkb@plen.ku.dk; Section for Microbial Ecology and Biotechnology, Department of Plant and Environmental Sciences, University of Copenhagen, Thorvaldsensvej 40, 1871 Frederiksberg C, Denmark. 


\section{ABSTRACT}

Stressors like metals or antibiotics can affect bacterial community permissiveness for plasmid uptake, but there is little knowledge about long-term effects of such stressors on the evolution of community permissiveness. We assessed the effect of more than 90 years of soil $\mathrm{Cu}$ contamination on bacterial community permissiveness (i.e. uptake ability) towards a $g f p$-tagged IncP-1 plasmid (pKJK5) introduced via an Escherichia coli donor. Plasmid transfer events from the donor to the recipient soil bacterial community were quantified and transconjugants fvere subsequently isolated by fluorescence activated cell sorting and identified by 16S rRNA gene amplicon sequencing. Transfer frequency of plasmid pKJK5 was reduced in bacterial communities extracted from highly $\mathrm{Cu}$ contaminated $\left(4526 \mathrm{mg} \mathrm{kg}^{-1}\right)$ soil compared to corresponding communities extracted from moderately $\left(458 \mathrm{mg} \mathrm{kg}^{-1}\right) \mathrm{Cu}$ contaminated soil and a low $\mathrm{Cu}$ reference soil $\left(15 \mathrm{mg} \mathrm{kg}^{-1}\right)$. The taxonomic composition of the transconjugal pools showed remarkable similarities irrespective of the degree of soil $\mathrm{Cu}$ contamination and despite contrasting compositions of the extracted recipient communities and the original soil communities. Permissiveness assessed at the level of individual operational taxonomic units (OTUs; 16S rRNA gene 97\% sequence similarity threshold) was only slightly affected by soil $\mathrm{Cu}$ level and high replicate variability of OTU-level permissiveness indicated a role of stochastic events in IncP-1,plasmid transfer or strain-to-strain permissiveness variability.

Keywords: Conjugal plasmid transfer, copper, horizontal gene transfer, plasmid permissiveness, soil bacterial community, transconjugants 


\section{Introduction}

Horizontal gene transfer (HGT) is a driving force for bacterial evolution and accelerates genomic diversification by incorporating new genomic elements (Frost et al. 2005; Sørensen et al. 2005; Harrison and Brockhurst 2012). Bacteria can acquire foreign DNA through transformation, transduction or conjugation. Conjugation refers to genetic material typically in the form of plasmids being transferred from bacterial donor cells to recipient cells during direct cell-to-cell contact to form transconjugants (Norman, Hansen and Sorensen 2009). Conjugation is generally considered the most important HGT mechanism for transfer of antibiotic resistance (von Wintersdorff et al. 2016; Enault et al. 2017), but conjugation also contributes to ecosystem services via environmental dissemination of catabolic genes for biodegradation of organic pollutants (Wang et al. 2010).

In soil, many abiotic and biotic factors may affect bacterial conjugation processes, including availability of nutrients or chemical stressors, spatial bacterial distribution and physiological status of bacteria potentially engaging in plasmid transfer (van Elsas and Bailey 2002; Sørensen et al. 2005; Aminov 2011; Heuer and Smalla 2012; Klümper et al. 2017; Fan et al. 2019). Soil metal contamination can impair bacterial growth, activity and survival and selects for metal tolerant bacterial communities with altered composition and an increased incidence of metal resistant bacteria (Berg et al. 2010, 2012; Brandt et al. 2010). Adaptive evolutionary responses to metal stress in soil can occur via adaptive point mutations in individual bacteria, but conjugal plasmid transfer allows for rapid dissemination of metal resistance determinants in bacterial communities (Sobecky and Coombs 2009; Heuer and Smalla 2012). Many large self- 
transmissible genetic elements are equipped with multiple genes encoding simultaneous resistance traits towards antibiotics, metals and biocides (Aminov and Mackie 2007). Transfer of conjugal plasmids between bacteria in metal polluted soil is therefore of particular concern due to the risk of metal induced co-selection of antibiotic resistance (Baker-Austin et al. 2006; Ashbolt et al. 2013; Pal et al. 2017; Zhao et al. 2019). This concern is further supported by the recent observations that metals such as $\mathrm{Cu}$ and $\mathrm{Zn}$ may constitute stronger selective agents for antibiotic resistance than antibiotic residues in soil (Song et al. 2017).

Previous studies of metal impacts on conjugal plasmid transfer have largely been performed using cultivation based studies relying on model bacteria (Aminov 2011; Heuer and Smalla 2012). However, the permissiveness for plasmid uptake varies dramatically between individual recipient bacterial strains and studies relying entirely on model bacteria thus havelittle predictive value for monitoring the transfer of plasmids in highly diverse bacterial communities (De La Cruz-Perera et al. 2012; Klümper et al. 2015). Further, only a small fraction of all bacteria is readily culturable, and the transfer frequency, as well as the host range of the plasmid may be greatly underestimated (Musovic et al. 2006).

Recent technical advances now make it possible to study the effect of environmental conditions on permissiveness for plasmid uptake at the bacterial community level. Community permissiveness has two components as it 'refers to the ability of a community to receive a plasmid, both in terms of transfer frequency and transconjugant phylogeny' (Klümper et al. 2017). We thus consider bacterial community permissiveness as an inherent property of a an assemblage of bacteria (i.e. a community) and it must therefore be quantified in assays where the recipient community is in direct contact with donor bacteria. It has been demonstrated that an extremely diverse fraction of the soil bacterial community can be permissive towards the broad 
host range IncP-1 plasmid pKJK5 when introduced via different bacterial donor strains (Klümper et al. 2014, 2015, 2017). In addition, one of these studies was the first to demonstrate a high sensitivity of bacterial community permissiveness towards short-term metal stress (Klümper et al. 2017). Hence, metal stress increased the permissiveness for some operational taxonomic units (OTUs, 97\% sequence similarity) by more than 1000 times, whereas a strong opposite trend was observed for other OTUs.

This study raises the question of how the observed modulation of community permissiveness by short-term metal stress ( $48 \mathrm{~h}$ ) compares to stress caused by long-term soil metal exposure. In other words, does long-term adaptation to toxic metals affect bacterial permissiveness towards the IncP-1 plasmid pKJK5 at the community or individual OTU level in a fashion similar to short-term metal stress? To address this question, we quantified, cell-sorted and taxonomically identified transconjugants to determine the permissiveness towards pKJK5 uptake in bacterial communities originating from two long-term copper contaminated soils as well as from a corresponding low $\mathrm{Cu}$ control soil. The sampling site, located in Hygum, Denmark, had been contaminated with $\mathrm{CuSO}_{4}$ from 1911 to 1924 (Strandberg et al. 2006). Previous investigations on the same soils have demonstrated that differences in various bacterial community attributes (i.e. composition, diversity, metatranscriptome dynamics, and resistance to $\mathrm{Cu}$ and antibiotics) could be linked specifically to differential $\mathrm{Cu}$ exposure (Berg et al. 2010, Berg et al., 2012; Thorsen et al., 2013; Nunes et al. 2016; Jacquiod et al. 2018). Hence, this field site enabled us to study the legacy effects of $\mathrm{Cu}$ contamination without significant confounding effects caused by other toxic elements or other edaphic factors. Specifically, we used a previously developed high-throughput method for the quantification, isolation and taxonomic identification of transconjugants (Klümper et at. 2017) to investigate the impact of long-term Cu stress in soil on the ability of bacterial 
community members to take up the broad-host-range IncP-1 plasmid pKJK5 from an E. coli model donor strain.

\section{Materials and methods}

\section{Soil sampling and bacterial community extraction}

Soil samples were collected at a depth of 0-20 cm from a well described $\mathrm{Cu}$ gradient field site in Hygum, Denmark (Strandberg et al. 2006; Berg et al. 2010, 2012; Arthur et al. 2012). Soil was sampled from each of three previously established field plots at the contaminated sites: MCC (moderately $\mathrm{Cu}$ contaminated; $458 \mathrm{mg} \mathrm{kg}^{-1} \mathrm{Cu}$ ), $\mathrm{HCC}$ (highly $\mathrm{Cu}$ contaminated; $4526 \mathrm{mg} \mathrm{kg}^{-1} \mathrm{Cu}$ ) contaminated sites and an adjacent control soil site $\left(15 \mathrm{mg} \mathrm{kg}^{-1} \mathrm{Cu}\right)(\mathrm{Nunes}$ et al., 2016). Soil samples were collected in December 2015 by taking nine soil cores per field plot (i.e. Control, MCC and HCC soil). The nine soil cores were divided into three replicate composite soil samples mixing three soil cores together for each replicate. The soil samples were sieved through a $2 \mathrm{~mm}^{2}$ mesh, homogenized and stored at $10{ }^{\circ} \mathrm{C}$ for up to a month before the experiment.

Bacterial communities from each soil replicate ( $25 \mathrm{~g})$ were extracted by Nycodenz density gradient centrifugation (Holmsgaard et al. 2011; Klümper, Dechesne and Smets 2014) (for details see supporting information; SI-1). Extracted bacteria were resuspended in sterile $0.9 \%$ saline solution, filtered through a $30 \mu \mathrm{m}$ filter and quantified through viability staining (Propidium iodide/SYBR green I) (Grégori et al. 2001; Manti et al. 2008) to adjust the concentration of recipient and $E$. coli donor cells to $3 \times 10^{7}$ cells $\mathrm{ml}^{-1}$. 


\section{Filter mating assay and quantification of transfer frequency}

E. coli MG1655::lacI ${ }^{q}:$ mCherry (Klümper et al. 2015) hosting the broad host range plasmid pKJK5-Plac-gfpmut3 (Bahl et al. 2007) served as the donor strain. The donor strain was chromosomally tagged with a $\operatorname{Tn} 7$ based gene cassette encoding constitutive $m$ Cherry red fluorescence and a constitutive LacI repressor preventing expression of the plasmid encoded $g f p$ in the donor strain. Hence, the gfpmut3 gene only became expressed upon successful plasmid pKJK5 transfer to a recipient cell, resulting in green fluorescent transconjugal cells. The red fluorescent donor cell and the green florescent transconjugants were subsequently detected by fluorescence microscopy or flow cytometry and sorted by FACS (Sørensen et al. 2005; Klümper, Dechesne and Smets 2014).

Plasmid transfer was evaluated by exposing Nycodenz extracted soil bacteria to the $E$. coli donor strain in solid surface filter mating assays. The donor and the soil derived recipient cells were mixed at 1:1 ratio on black polycarbonate filter $(0.2 \mu \mathrm{m}$ pore size, $25 \mathrm{~mm}$ diameter) placed on top of a low-nutrient medium (Luo 2015)(for details see supporting information; SI-2) resulting in approximately 100,000 bacteria $/ \mathrm{mm}^{2}$ filter surface area. Five replicate filter matings were performed for each of the three biological replicates of all three soil types. In order to evaluate the effect of donor cells on recipient community composition, 'reference' filters exclusively hosting the recipient communities or recipient communities mixed with a plasmid free version of the donor strain $E$. coli MG1655::lacl ${ }^{q}:: m$ Cherry were also prepared. All filter mating plates were incubated at $25^{\circ} \mathrm{C}$ in the dark for 48 hours. 
Conjugation events were detected by stereomicroscopy and quantified by digital image analysis (Image Pro plus 7.1) as previously described (Klümper et al. 2014, 2017; Klümper, Dechesne and Smets 2014). The transfer frequency was defined as the number of conjugation events counted on the whole filter area divided by the number of introduced recipient cells at the start of the mating experiments.

\section{Florescence activated cell sorting (FACS) and sequencing}

Cells from each filter mating combination between the donor and recipient community were collected by transferring the filter into $2 \mathrm{ml}$ of a $0.9 \% \mathrm{NaCl}$ solution followed by vortexing at highest speed for $3 \mathrm{~min}$. Transconjugant cells were isolated by triple gated fluorescence activated cell sorting (FACS). FACS was carried out using a FACS Aria IIIu (Becton Dickinson Biosciences, San Jose, CA) with the following settings: forward scatter (FSC) $=505 \mathrm{~V}$, side scatter $(\mathrm{SSC})=308 \mathrm{~V}$, and detectors for green $(\mathrm{BP}$ filter $530 / 30 \mathrm{~nm})$ and red fluorescence $(\mathrm{BP}$ filter $610 / 20 \mathrm{~nm}$ ) were set at $508 \mathrm{~V}$ and $500 \mathrm{~V}$, respectively. Both cell counting and sorting were performed and analyzed with the software BDFACSDiva ${ }^{\mathrm{TM}} \mathrm{v} 6.1 .3$. The setup for gating and sorting was performed based on bacterial size, green fluorescence and exclusion of red fluorescent donor cells as described previously (Klümper, Dechesne and Smets 2014; Klümper et al. 2017) (for details see supporting information; SI-3). The corresponding recipient community cells from the same mating plates were sorted separately based on bacterial size and excluding red fluorescent donor cells. For each sample, a minimum of 20,000 recipient cells or gfpmut3 expressing transconjugants were sorted. All sorted cells were collected in $0.9 \% \mathrm{NaCl}$ solution, lysed (Lyse and Go PCR reagent, Thermo Scientific, Waltham, MA, USA) and followed by 16S rRNA gene amplicon sequencing as described previously (Klümper et al. 2017) (for details see supporting information; SI-4). Bacterial DNA was also extracted directly from the original soil 
samples and from soil bacterial cells harvested by Nycodenz extraction using the FastDNA SPIN for soil kit (MP Biomedicals) as described by manufacturer's instructions and used for 16S rRNA gene amplicon sequencing to analyze the bacterial community structure and diversity of the recipient community (see SI-4 for details).

\section{Sequence analysis}

Raw fastq files were processed with BioDSL (https://github.com/maasha/BioDSL). Primers and diversity spacers were identified and truncated with trim_primer. Paired ends were matched with assemble_pairs and any sequences shorter than $100 \mathrm{bp}$ were discarded, and finally dereplicated using dereplicate_seq. The sequences were clustered at 97\% with cluster_otus, a wrapper around usearch 7.0.1090 (Edgar 2010). Chimeras were checked with uchime_ref that utilizes the same version of usearch with the Ribosomal Database Project (RDP) database as reference (Wang et al. 2007). The resulting sequences were classified using classify_seq against the RDP database (version 9). Align_seq_mothur (Schloss et al. 2009), a wrapper around mothur's align.seqs function for aligning OTUs against a RDP template. Finally, a phylogenetic tree was built from the alignment using write_tree, a wrapper function for FastTree (Price, Dehal and Arkin 2009). Phylogenetic trees displayed were constructed using iTOL v3 (http://itol.embl.de/) (Letunic and Bork 2007).

\section{OTU level permissiveness analysis}

The apparent permissiveness (AP) of an OTU was defined as follows (Klümper et al. 2017):

$A P_{i}=\frac{T_{i}}{R_{i}}$, where $T_{i}$ and $R_{i}$ refer to the relative abundance of $\mathrm{OTU}_{i}$ in the transconjugal pool and the recipient community, respectively. In order to evaluate the change of permissiveness of individual OTUs after long-term $\mathrm{Cu}$ contamination, individual OTU permissiveness changes $(\delta)$ 
were calculated as $\delta i=\frac{A P_{i_{\text {incu }} \text { soil }}}{A P_{i_{-} \text {control soil }}}$, where $A P_{i_{-} C u \text { soil }}$ equals an OTU's apparent permissiveness in either $\mathrm{HCC}$ or MCC soil and $A P_{i_{-} \text {control soil }}$ equals the same OTU's apparent permissiveness in control soil. A total of 23 OTUs were selected for subsequent individual OTU permissiveness analysis based on the following two criteria: 1) OTU is present in all recipient communities and 2) average OTU relative abundance is above $0.01 \%$ across all transconjugant pools.

\section{Statistics}

Richness ( $\alpha$-diversity) of all sampled communities was calculated in R using the 'phyloseq' package (McMurdie and Holmes 2013) with at a minimum depth of 12,110 reads. Rarefaction curves were obtained using the PAST software ver.2.17 (Hammer, Harper and Ryan 2001). Differences of the taxonomic composition of transconjugant pools and recipient communities (phylogenetic distance between samples) were visualized by non-metric dimensional scaling (NMDS) analysis using weighted unifrac distances as input data in $\mathrm{R}$ with the package phyloseq (McMurdie and Holmes, 2013). The effects of long-term Cu contamination on the taxonomic composition of transconjugal pools and recipient communities were tested by permutational multivariate analysis of variance (PerMANOVA) in R using the 'adonis' function with 10,000 permutations in the 'vegan' package. Differences of transfer frequency and observed richness of recipient communities among control soil, MCC soil and HCC soil were tested by one-way ANOVA in Sigma plot 13.0.

\section{Accession numbers}

The partial 16S rRNA gene sequences have been deposited in the NCBI Sequence Read Archive (SRA) database under BioProject ID PRJNA559939. 


\section{Results}

\section{Decreased bacterial fraction is permissive in highly $\mathrm{Cu}$ contaminated soil}

We determined the transconjugant per donor (T/D) ratio, as inferred from flow cytometric counts at the end of the $48 \mathrm{~h}$ mating, to compare transfer frequencies of plasmid pKJK5 between the three recipient communities. The $\mathrm{T} / \mathrm{D}$ ratio was significantly lower (one way ANOVA, $\mathrm{p}<0.05$; $n=3$; Figure S1) for the bacterial community extracted from the HCC soil $(0.53 \% \pm 0.26 \%)$ as compared to the corresponding communities from MCC soil $(17.8 \% \pm 5.5 \%)$ and control soil $(12.8 \% \pm 4.5 \%)$. Potential bias should be noticed here as the flow cytometric counts could not distinguish between real pKJK5 transfer events and subsequent preferential growth of transconjugants or donors. However, we find it highly unlikely that this preferential growth bias could solely explain the lower T/D ratio obtained for the HCC soil as compared to the MCC and control soils. Furthermore, estimates based on fluorescence microscopy data confirmed the trend obtained for T/D ratios (Figure S2).

\section{The composition of transconjugal pools show higher similarity than their corresponding}

\section{recipient soil bacterial communities}

16S rRNA gene amplicon sequencing was performed to analyze the phylogenetic composition of the transconjugal pools; i.e. all FACS separated green fluorescent cells. Control experiments showed that the presence of $E$. coli donor cells did not affect recipient soil bacterial community composition (see Supporting Information SI-5 and Figure S3 for details). Transconjugant pools from all three soils encompassed 296 OTUs, including 105 abundant OTUs $(>0.01 \%$ relative abundance across all transconjugal pools) distributed across 10 different phyla (Figure 1). These 
included the dominant Proteobacteria (Alpha, Beta, Gamma and Delta), other Gram negative phyla (Bacteroidetes, Nitrospira, Planctomycetes, Gemmatimonadetes, Spirochaetes and Verrucomicrobia), and three Gram positive phyla (Firmicutes, Actinobacteria and Chloroflexi). The investigated IncP-1 plasmid pKJK5 was transferred to all abundant phyla within the recipient community sorted from the filters ( $>0.01 \%$ relative abundance across all transconjugants pools) as well as to most rare phyla $(<0.01 \%$ relative abundance across all transconjugants pools) except the phylum Ignavibacteriae (Figure S4).

At the phylum level, all transconjugal pools were dominated ( $>50 \%$ ) by Proteobacteria (mainly Gamma-subgroup), while other rarer phyla were detected only at specific Cu contamination levels. For example, the phylum Gemmatimonadetes was detected in all recipient communities, but only permissive to the introduced plasmid when originating from MC C or control soil. By contrast, the phylum Planctomycetes was only detected in transconjugal pools from either the HCC or MCC soils. Further, the phylum Spirochaetes was only detected in transconjugal pools and the recipient community from the HCC soil.

In order to analyze the $\mathrm{Cu}$ impacts on transconjugant pools at higher taxonomic resolution, further analysis was performed at the OTU level. All transconjugal pools showed coverage above $96 \%$ at a sampling depth of 12,110 sequences (see Figure S5 for rarefaction curves). The transconjugal pool OTU richness ( $\alpha$-diversity; mean $\pm \mathrm{SE} ; \mathrm{n}=3$ ) decreased from $86 \pm 9$ OTUs in the control and $112 \pm 51$ OTUs in the MCC soil to only $64 \pm 7$ OTUs in the HCC soil. Likewise, observed OTUrichness of the corresponding recipient community was significantly lower $(78 \pm 5$ OTUs) in the HCC soil ( $\mathrm{p}=0.013$, one way ANOVA, $n=3$ ) as compared to $103 \pm 5$ and $89 \pm 8$ OTUs in MCC and control soil, respectively. However, the fraction of total permissive OTUs in the 
recipient community only decreased slightly from $68.5 \%$ in control soil to $66.5 \%$ in the MCC soil and $52.1 \%$ in the HCC soil.

Remarkably, the taxonomic composition within the transconjugal pools originating from the three different soils was highly similar (Figure 2). Although only 39 out of 263 OTUs in total were shared between all three soil communities, these shared OTUs represented $96.2 \%$ of the total sequences from the transconjugal pools. Dissimilarity analysis based on Bray-Curtis distance of transconjugal pools from different soils indicated that the transconjugal pools from the MCC soil and the control soil were more similar than the transconjugal pools from the HCC soil (Figure S6), but these differences were subtle and did not generate a significant soil clustering pattern in the non-metric 2-dimensional scaling (NMDS) plot (Figure 3). Hence, transconjugal pools from the three contrasting soils clustered together, whereas the recipient communities from the HCC soil clustered significantly apart from the MCC and control soils (Fígure 3; Figure S7; Adonis test, $\mathrm{p}<0.001)$.

\section{Limited long-term $\mathrm{Cu}$ effect on OTU-level permissiveness}

In order to further investigate the long-term impacts of soil $\mathrm{Cu}$ contamination level on OTU level permissiveness, 23 abundant OTUS were selected based on the criteria that OTUs were present in all recipient communities with an average relative abundance above $0.01 \%$ across all transconjugant pools (Figure 4; Figure S8). OTU-level apparent permissiveness $\left(A P_{i}\right)$ were consistent across soil Cu levels for most OTUs (Figure S8). Some OTUs including Pedobacter OTU 7, Janthinobacterium OTU 2, Stenotrophomonas OTU 120, and Escherichia/Shigella OTU 3 were consistently underrepresented in transconjugant pools for all soils, whereas only Pseudomonas OTU 0 was consistently overrepresented in all soils. Overall, there was no clear $\mathrm{Cu}$ impact on the permissiveness observed for the 23 selected OTUs. The only exception was 
Pseudomonas OTU 14, which was more than 2-fold (average \pm standard deviation, $2.60 \pm 0.63$ ) over-represented in the transconjugal pool for control soil and more than 26 -fold $(156 \pm 134$ $\mathrm{p}=0.091$, t-test against 0 ) underrepresented for HCC soil with an intermediate effect observed in the MCC soil (Figure S8). When comparing the permissiveness of individual OTUs after longterm $\mathrm{Cu}$ exposure to their permissiveness in the control soil (Figure 4), OTUs generally did not show increased permissiveness $(\delta)$ with increasing soil $\mathrm{Cu}$ level across all three biological replicates. The only exception was Pedobacter OTU 7, which was exclusively permissive in the HCC and MCC soils, despite being abundant in the control soil. Across all three biological replicates, Pseudomonas OTU 401 displayed more than 37 -fold $(44 \pm 6, \mathrm{p}=0.0036)$ and more than 3-fold (4.7 $\pm 1.3, \mathrm{p}=0.013)$ decreased permissiveness in HCC and MCC søils, respectively.

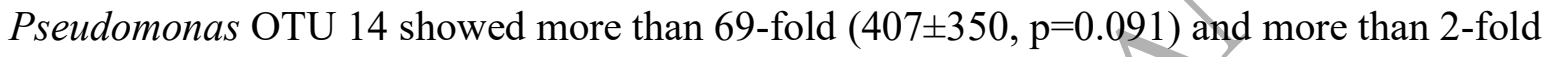
(5.3 $\pm 5.0, \mathrm{p}=0.056)$ decreased permissiveness in HCC and MCC soils, respectively. Across all three biological replicates, both Janthinobacterium OTU 2 (4.9 2.6 fold, $\mathrm{p}=0.043$ ) and Afipia OTU 5 (4.5 \pm 1.6 fold, $\mathrm{p}=0.021$ ) displayed more than 2-fold decreased permissiveness in MCC soil, whereas Noviherbaspirillum OTU1128 $(28 \pm 29, \mathrm{p}=0.12)$ and Pseudomonas OTU 2065 $(21.4 \pm 25.4, \mathrm{p}=0.14)$ showed more than 5 -fold and more than 3 -fold decreased permissiveness in HCC soils, respectively (Figure 4). In conclusion, we note a tendency for decreased OTU-level permissiveness with increasing soil $\mathrm{Cu}$ level, but also a considerable replicate-to-replicate variability.

\section{Discussion}

Our study took advantage of a previously developed fluorescence marker gene based approach to detect IncP-1 plasmid pKJK5 transfer events and subsequently isolate and identify 
transconjugants from the complex communities using fluorescence activated cell sorting (FACS) and subsequent 16S rRNA gene amplicon sequencing (Klümper et al. 2015, 2017). In accordance with recent studies applying the same experimental approach (Jacquiod et al. 2017; Li et al. 2018; Fan et al. 2019), we here demonstrate the transfer of the IncP-1 plasmid pKJK5 from E. coli to a remarkably wide taxonomic range (10 phyla) of both Gram negative and Gram positive soil bacteria during 48 hours of mating experiments. In this context it is important to differentiate between plasmid host range and plasmid replication range as plasmids initially taken up may subsequently be lost if the plasmid cannot replicate in its host. However, a very recent study specifically investigated the persistence of IncP-1 plasmid pKJK5 in bacterial communities derived from a sewage treatment plant and demonstrated extensive plasmid retention in diverse bacterial phylotypes during a 60 -generation experiment even at conditions that were nonselective for plasmid retention and non-conducive for plasmid transfer ( $\mathrm{Li}$ et al., 2020).

Even though large fractions of the recipient communities extracted from all soils remained permissive towards pKJK5, we also observed a substantially decreased transfer frequency of pKJK5 in the bacterial community extracted from the HCC soil as compared to corresponding communities from control and MCC soils (Figures S1 and S2). This effect is consistent with previous reports of reduced microbial activity in the most contaminated part of the studied soil $\mathrm{Cu}$ gradient (Arthur et al. 2012; Brandt, unpublished data).

Consistent with previous studies of the Hygum soil Cu gradient (Berg et al., 2012; Thorsen et al., 2013; Nunes et al. 2016), we observed contrasting composition and lower OTU richness of the recipient community in the HCC soil relative to the control and MCC soils. Nevertheless, highly similar taxonomic compositions of the transconjugal pools were observed in all three soils (Figure 3). This suggests that the realized host range for specific plasmids can remain remarkably 
unaffected by long-term soil metal contamination. Our results also demonstrate that more than 90 years of differential field soil $\mathrm{Cu}$ exposure did not dramatically influence the fraction of permissive OTUs in the recipient community. Hence, the fraction of total permissive OTUs only decreased slightly from $68.5 \%$ in the control soil to $66.5 \%$ in the MCC soil and $52.1 \%$ in the HCC soil.

A possible explanation for this slight reduction in community permissiveness could be that some HCC soil bacteria already had acquired IncP-1 plasmids encoding $\mathrm{Cu}$ resistance thereby preventing them from taking up the pKJK5 from E. coli. This explanation is consistent with data from a Hygum soil strain collection demonstrating that isolates from the HCC soil contained significantly more plasmids than corresponding strains from the control soil (Luo 2015). Indeed, the percentages of isolates carrying detectable plasmids were $45.7 \%$ and $21.1 \%$ for the $\mathrm{HCC}$ and control soil, respectively. Interestingly, co-selection of $\mathrm{Cu}$ and antibiotic resistance has been demonstrated in two independent studies of the Hygum soil Cu gradient (Berg et al. 2010; Luo 2015). Environmentally relevant concentrations of Cu has also been shown to co-select antibiotic resistance in other soils (Hu et al. 2016; Song et al. 2017; Kang et al. 2018; Zhao et al. 2019) implicating that soil $\mathrm{Cu}$ contamination represents a risk for environmental development and transfer of antibiotic resistance to humans (Ashbolt et al. 2013).

It has been proposed that low, environmentally relevant concentrations of antibiotics and metals may increase rates of bacterial evolvability in part via stimulation of conjugal plasmid transfer (Gillings and Stokes 2012; Zhang et al. 2019). By contrast, our data indicate that soil $\mathrm{Cu}$ contamination decreased community permissiveness for the uptake of IncP-1 plasmid pKJK5. It should be noted that we studied the plasmid transfer process in the absence of growth benefit for transconjugal cells and that we did not monitor the long-term fate of the introduced plasmid in 
soil (Fan et al. 2019). Hence, environmental selection of plasmids encoding metal resistance can probably 'compensate' for reduced plasmid transfer frequency thereby allowing for enrichment of resistance plasmids in severely metal contaminated soils. Finally, it should also be mentioned here that horizontal gene transfer may occur by other means than plasmid transfer and that these gene transfer processes can be affected differently by $\mathrm{Cu}$. A recent metatranscriptomics study is of particular interest as it demonstrated an unexpected, $\mathrm{Cu}$-dependent dominance of phage-related mRNA sequences accounting for $\sim 30 \%$ of annotated mRNA in the HCC soil (Jacquiod etal., 2018).

Our study of long-term $(90+$ yrs) soil $\mathrm{Cu}$ effects on bacterial community permissiveness for IncP1 plasmid pKJK5 uptake can be compared to a recent study employing the same model plasmid and bacterial communities from a low-Cu agricultural soil for studying short-term (48 h) metal stress effects on community permissiveness (Klümper et al.,2017). Both the short- and long-term study on $\mathrm{Cu}$ modulation of conjugal plasmid transfer showed that transfer frequencies of plasmid pKJK5 consistently decreased compared to the reference (i.e. control soil) conditions. However, the individual permissiveness of OTUs showed contrasting patterns in the long- and short-term studies. In the latter, $\mathrm{Cu}$ stress modulated the conjugation process by in- or decreasing the permissiveness for specific OTUs by up to 1000- and 10,000-fold, respectively (Klümper et al., 2017). By contrast, the level of OTU-level permissiveness modulation was modest in our longterm study. Hence, when comparing the 23 core permissive OTUs, only one OTU (Pedobacter OTU 7) showed increased individual permissiveness in both MCC and HCC soils (Figure 4). Individual permissiveness of 6 OTUs from MCC or HCC soils decreased by more than 2-fold compared to the control soil and only for 2 OTUs did permissiveness decrease by more than 10 fold in the HCC soil (Figure 4). Collectively, these data clearly indicate different community 
responses to short-term (48 h) and long-term $(90+$ yrs $) \mathrm{Cu}$ exposure. When discussing OTU-level permissiveness, it has previously been established that even closely related strains belonging to the same bacterial species can differ in permissiveness for plasmid uptake by orders of magnitude (Heuer et al., 2010). Hence, it should be mentioned here that the observed effects of $\mathrm{Cu}$ stress on OTU-level permissiveness will probably to some extent be masked by the presence of different strains differring in permissiveness within each OTU.

In conclusion, our results indicate that the transfer frequency of an IncP-1 plasmid (pKJK5) during filter matings were lower for bacteria extracted from HCC soil than for bacteria extracted from low-Cu control soil or MCC soil. However, the fraction of permissive OTUs was only marginally lower in $\mathrm{HCC}$ soil than in control and MCC soils. Further, transconjugant pools encompassed 10 different phyla and were remarkably similar for all studied soils even though they contained contrasting recipient communities. Finally, we observed considerable replicate variability for transconjugant pool compositon and especially for individual OTU-level permisiveness (Heuer et al., 2010). Our results thus suggest that a defined subset of OTUs will be able to take up the IncP-1 plasmid pKJK5 across sites differentially contaminated with metals, but also that stochastic conjugation-related events (Delavat et al. 2017) or strain-to-strain variability (Heuer et al., 2010) may make it difficult to predict the fate of conjugal plasmids and their genes (e.g. antibiotic resistance genes). Finally, our results indicate that long-term $\mathrm{Cu}$ contamination does not select for bacterial communities with increased evolvability by virtue of increased plasmid permissiveness as suggested previously (Gillings and Stokes 2012). By contrast, bacterial plasmid transfer frequencies and the fraction of permissive OTUs are likely to be lower in highly metal impacted soils than in corresponding reference soils. 


\section{Funding}

This work was supported by Center for Environmental and Agricultural Microbiology (CREAM) funded by Villum Foundation; the National natural Science foundation of China [41907358] and the European Union's Horizon 2020 research and innovation program under Marie SkłodowskaCurie grant agreement [751699].

\section{Acknowledgements}

We thank SM Milani for technical assistance in FACS sorting, Luma George Odish and Waleed Abu Al-Soud for carrying out the amplicon sequencing, and Asker Daniel Brejnrod for assistance with DNA sequence analysis.

\section{Declaration of interests: None}

\section{References}

Aminov RI. Horizontal gene exchange in environmental microbiota. Front Microbiol 2011;2, 158.

Aminov RI, Mackie RI. Evolution and ecology of antibiotic resistance genes. Fems Microbiol Lett 2007;271:147-61.

Arthur E, Moldrup P, Holmstrup M et al. Soil microbial and physical properties and their relations along a steep copper gradient. Agric Ecosyst Environ 2012;159:9-18.

Ashbolt NJ, Amezquita A, Backhaus T et al. Human Health Risk Assessment (HHRA) for environmental development and transfer of antibiotic resistance. Env Heal Perspect 2013;121:993-1001.

Bahl MI, Hansen LH, Goesmann A et al. The multiple antibiotic resistance IncP-1 plasmid pKJK5 isolated from a soil environment is phylogenetically divergent from members of the previously established $\alpha, \beta$ and $\delta$ sub-groups. Plasmid 2007;58:31-43. 
Baker-Austin C, Wright MS, Stepanauskas R et al. Co-selection of antibiotic and metal resistance. Trends Microbiol 2006;14:176-82.

Berg J, Brandt KK, Al-Soud WA et al. Selection for Cu-Tolerant Bacterial Communities with Altered Composition, but Unaltered Richness, via Long-Term $\mathrm{Cu}$ Exposure. Appl Environ Microbiol 2012;78:7438-46.

Berg J, Thorsen MK, Holm PE et al. Cu Exposure under Field Conditions Coselects for Antibiotic Resistance as Determined by a Novel Cultivation-Independent Bacterial Community Tolerance Assay. Environ Sci Technol 2010;44:8724-8.

Brandt KK, Frandsen RJN, Holm PE et al. Development of pollution-induced community tolerance is linked to structural and functional resilience of a soil bacterial community following a five-year field exposure to copper. Soil Biol Biochem 2010;42:748-57.

Delavat F, Miyazaki R, Carraro N et al. The hidden life of integrative and conjugative elements. FEMS Microbiol Rev 2017;41:512-37.

Edgar RC. Search and clustering orders of magnitude faster than BLAST. Bioinformatics 2010;26:2460-1.

van Elsas JD, Bailey JM. The ecology of transfer of mobile genetic elements. FEMS Microbiol Ecol 2002;42:187-97.

Enault F, Briet A, Bouteille L et al. Phages rarely encode antibiotic résistance genes: a cautionary tale for virome analyses. ISME J 2017;11:237-47.

Fan X-T, Li H, Chen Q-L et al. Fate of Antibiotic Resistant Pseudomonas putida and Broad Host Range Plasmid in Natural Soil Microcosms. Front Microbiol 2019;10:194.

Frost LS, Leplae R, Summers AO et al. Mobile genetic elements: the agents of open source evolution. Nat Rev Micro 2005;3:722-32.

Gillings MR, Stokes HW. Are humans increasing bacterial evolvability? Trends Ecol Evol 2012;27:346-52.

Grégori G, Citterio S, Ghiani A et al. Resolution of Viable and Membrane-Compromised Bacteria in Freshwater and Marine Waters Based on Analytical Flow Cytometry and Nucleic Acid Double Staining. Appl Environ Microbiol 2001;67:4662-70.

Hammer Ø, Harper DA., Ryan PD. PAST: Paleontological Statistics Software Package for Education and Data Analysis. Palaeontol Electron 2001;4(1):1-9.

Harrison E, Brockhurst MA. Plasmid-mediated horizontal gene transfer is a coevolutionary process. Trends Microbiol 2012;20:262-7.

Heuer H, Ebers J, Weinert $\mathrm{N}$ et al. Variation in permissiveness for broad-host-range plasmids among genetically indistinguishable isolates of Dickeya sp. from a small field plot. FEMS Microbiol Ecol 2010;73:190-6. 
Heuer H, Smalla K. Plasmids foster diversification and adaptation of bacterial populations in soil. FEMS Microbiol Rev 2012;36:1083-104.

Holmsgaard PN, Norman A, Hede SC et al. Bias in bacterial diversity as a result of Nycodenz extraction from bulk soil. Soil Biol Biochem 2011;43:2152-9.

$\mathrm{Hu} \mathrm{H}$, Wang JT, Li J et al. Field-based evidence for copper contamination induced changes of antibiotic resistance in agricultural soils. Environ Microbiol 2016;00:1-14.

Jacquiod S, Brejnrod A, Morberg SM et al. Deciphering conjugative plasmid permissiveness dynamics in wastewater microbiomes. Mol Ecol 2017, DOI: 10.1111/ijlh.12426.

Jacquiod S, Cyriaque V, Riber L et al. Long-term industrial metal contamination unexpectedly shaped diversity and activity response of sediment microbiome. J Hazard Mater 2018;344:299-307.

Kang W, Zhang Y-J, Shi X et al. Short-term copper exposure as a selection pressure for antibiotic resistance and metal resistance in an agricultural soil. Environ Sci Pollut Res 2018;25:29314-24.

Klümper U, Dechesne A, Riber L et al. Metal stressors consistently modulate bacterial conjugal plasmid uptake potential in a phylogenetically conserved manner. ISME J 2017;11:152-65.

Klümper U, Dechesne A, Smets B. Protocol for Evaluating the Permissiveness of Bacterial Communities Toward Conjugal Plasmids by Quantification and Isolation of Transconjugants. Humana Press, 2014, 1-14.

Klümper U, Droumpali A, Dechesne A et al. Novel assay to measure the plasmid mobilizing potential of mixed microbial communities. Front Microbiol 2014;5, DOI:

10.3389/fmicb.2014.00730.

Klümper U, Riber L, Dechesne A et al. Broad host range plasmids can invade an unexpectedly diverse fraction of a soil bacterial community. Isme J 2015;9:934-45.

De La Cruz-Perera CI, Ren D, Blanchet M et al. The ability of soil bacteria to receive the conjugative IncP1 plasmid, pKJK10, is different in a mixed community compared to single strains. 2012, DOI: 10.111/1574-6968.12036.

Letunic I, Bork P. Interactive Tree Of Life (iTOL): An online tool for phylogenetic tree display and annotation. Bioinformatics 2007;23:127-8.

Li L, Dechesne A, He Z et al. Estimating the Transfer Range of Plasmids Encoding Antimicrobial Resistance in a Wastewater Treatment Plant Microbial Community. Environ Sci Technol Lett 2018;5:260-5.

Li L, Dechesne A, Madsen JS et al. Plasmids persist in a microbial community by providing fitness benefit to multiple phylotypes. The ISME Journal 2020;14:1170-81. 
Luo W. The soil mobilome: A direct approach to study plasmid-encoded functional responses to long-term copper contamination. 2015. PhD thesis, University of Copenhagen, http://www2.bio.ku.dk/bibliotek/phd/Wenting\%20Luo.pdf.

Manti A, Boi P, Falcioni T et al. Bacterial Cell Monitoring in Wastewater Treatment Plants by Flow Cytometry. Water Environ Res 2008;80:346-54.

McMurdie PJ, Holmes S. Phyloseq: An R Package for Reproducible Interactive Analysis and Graphics of Microbiome Census Data. PLoS One 2013;8, DOI: 10.1371/journal.pone.0061217.

Musovic S, Oregaard G, Kroer N et al. Cultivation-independent examination of horizontal transfer and host range of an IncP-1 plasmid among gram-positive and gram-negative bacteria indigenous to the barley rhizosphere. Appl Environ Microbiol 2006;72:6687-92.

Norman A, Hansen LH, Sorensen SJ. Conjugative plasmids: vessels of the communal gene pool. Philos Trans R Soc L B Biol Sci 2009;364:2275-89.

Nunes I, Jacquiod S, Brejnrod A et al. Coping with copper: legacy effect of copper on potential activity of soil bacteria following a century of exposure. FEMS Microbiol Ecol 2016;92:175.

Pal C, Asiani K, Arya S et al. Metal Resistance and Its Association With Antibiotic Resistance. Adv Microb Physiol 2017;70:261-313.

Price MN, Dehal PS, Arkin AP. FastTree: Computing Large Minimum Evolution Trees with Profiles instead of a Distance Matrix. Mol Biol Evol 2009;26:1641-50.

Schloss PD, Westcott SL, Ryabin T et al. Introducing mothur: Open-source, platformindependent, community-supported software for describing and comparing microbial communities. Appl Environ Microbiol 2009;75:7537-41.

Sobecky PA, Coombs JM. Horizontal gene transfer in metal and radionuclide contaminated soils. Methods in Molecular Biology (Clifton, N.J.). United States, 2009, 455-72.

Song J, Rensing C, Holm PE et al. Comparison of Metals and Tetracycline as Selective Agents for Development of Tetracycline Resistant Bacterial Communities in Agricultural Soil. Environ Sci Technol 2017,51:3040-7.

Sørensen SJ, Bailey M, Hansen LH et al. Studying plasmid horizontal transfer in situ: a critical review. Nat Rev Micro 2005;3:700-10.

Strandberg B, Axelsen JA, Pedersen MB et al. Effect of a copper gradient on plant community structure. Environ Toxicol Chem 2006;25:743-53.

Thorsen MK, Brandt KK, Nybroe O. Abundance and diversity of culturable Pseudomonas constitute sensitive indicators for adverse long-term copper impacts in soil. Soil Biol Biochem 2013;57:933-5.

Wang Q, Garrity GM, Tiedje JM et al. Naïve Bayesian Classifier for Rapid Assignment of rRNA Sequences into the New Bacterial Taxonomy. Appl Environ Microbiol 2007;73:5261- 7. 
Wang Y, Li H, Zhao W et al. Induction of toluene degradation and growth promotion in corn and wheat by horizontal gene transfer within endophytic bacteria. Soil Biol Biochem 2010;42:1051-7.

von Wintersdorff CJH, Penders J, van Niekerk JM et al. Dissemination of Antimicrobial Resistance in Microbial Ecosystems through Horizontal Gene Transfer. Front Microbiol 2016;7:173.

Zhao Y, Cocerva T, Cox S et al. Evidence for co-selection of antibiotic resistance genes and mobile genetic elements in metal polluted urban soils. Sci Total Environ 2019;656:512-20.

Zhang S, Wang Y, Song H et al. Copper nanoparticles and copper ions promote horizontal transfer of plasmid-mediated multi-antibiotic resistance genes across bacterial genera. Environ Int 2019;129:478-87. 


\section{Figure 1}

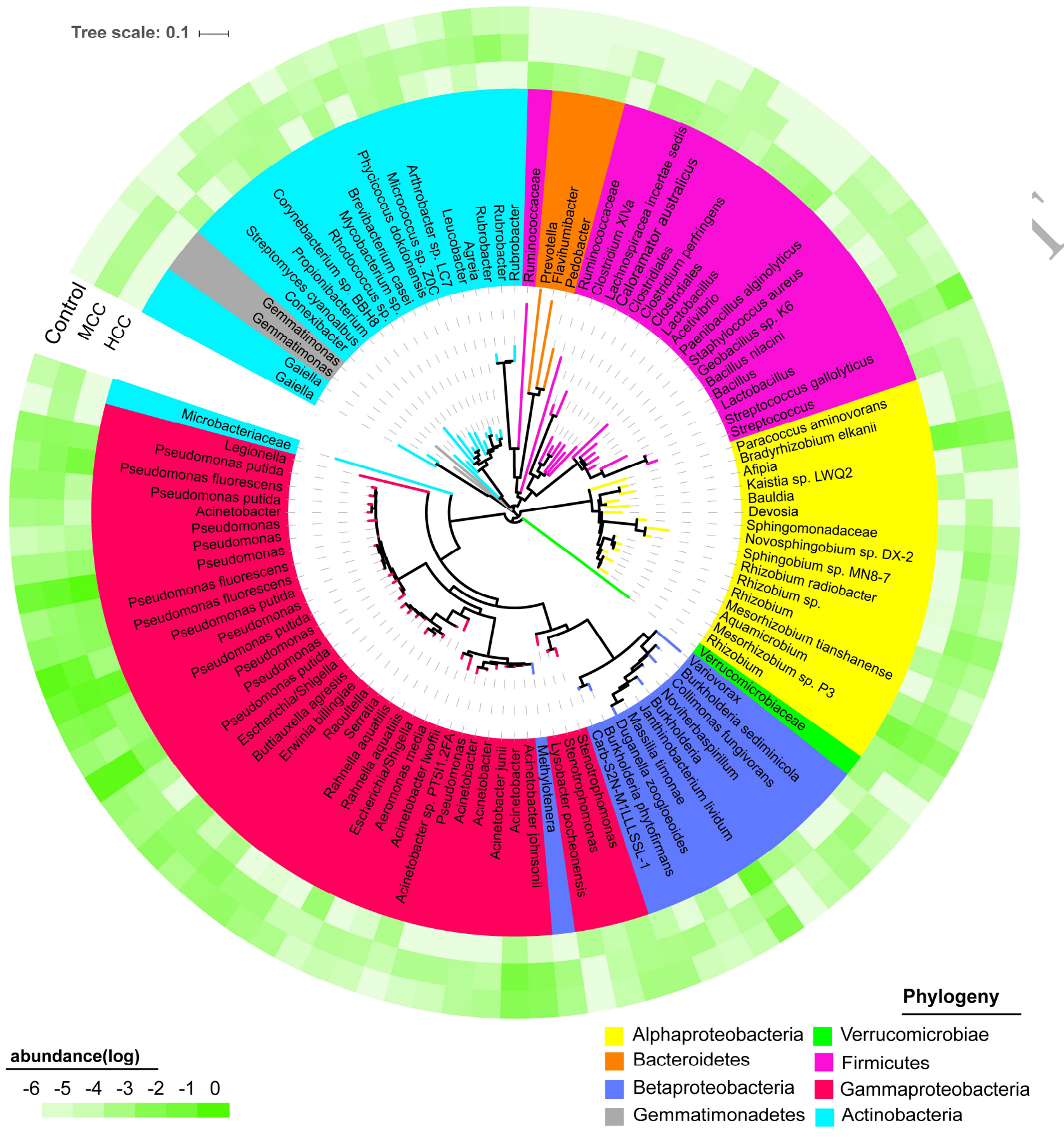

Figure 1. Phylogenetic tree (approximate maximum likelyhood) showing the 105 most abundant OTUs within the transconjugant pools $(>0.01 \%$ relative abundance across all transconjugant pools). Colors of the branches mark the different phylogenetic groups. The three green heatmap- 
circles at the periphery of the tree represent log-transformed relative OTU abundance from different transconjugant pools; i.e low-Cu control soil (Control), moderately $\mathrm{Cu}$ contaminated soil (MCC), and highly $\mathrm{Cu}$ contaminated soil (HCC). 


\section{Figure 2}
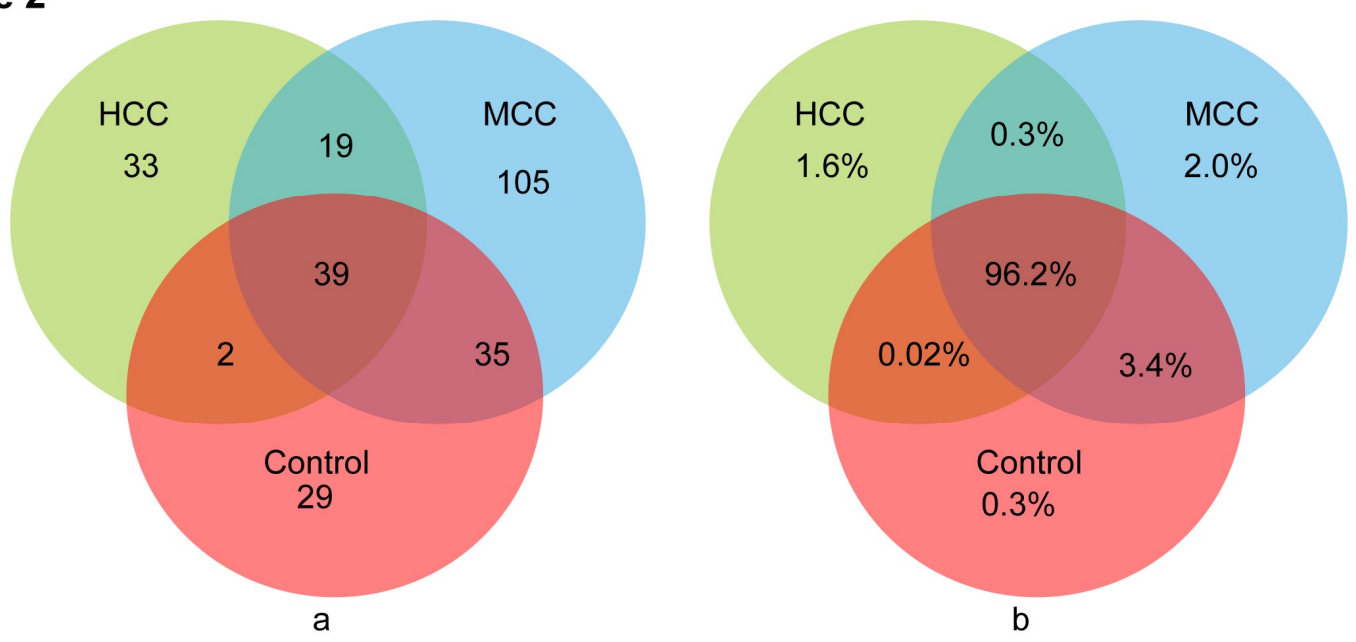

Figure 2. Venn diagrams of the transconjugal pools from the three different soils; i.e. low-Cu control soil (Control), moderately contaminated soil (MCC), and highly contaminated soil (HCC). Venn diagrams are presented for OTU incidence (a) and for OTU relative abundance (b). OTUs were defined at the $97 \%$ sequence similarity level and sequences from treatment replicates were pooled to get a population size of 24,200 sequences per treatment. 
Figure 3

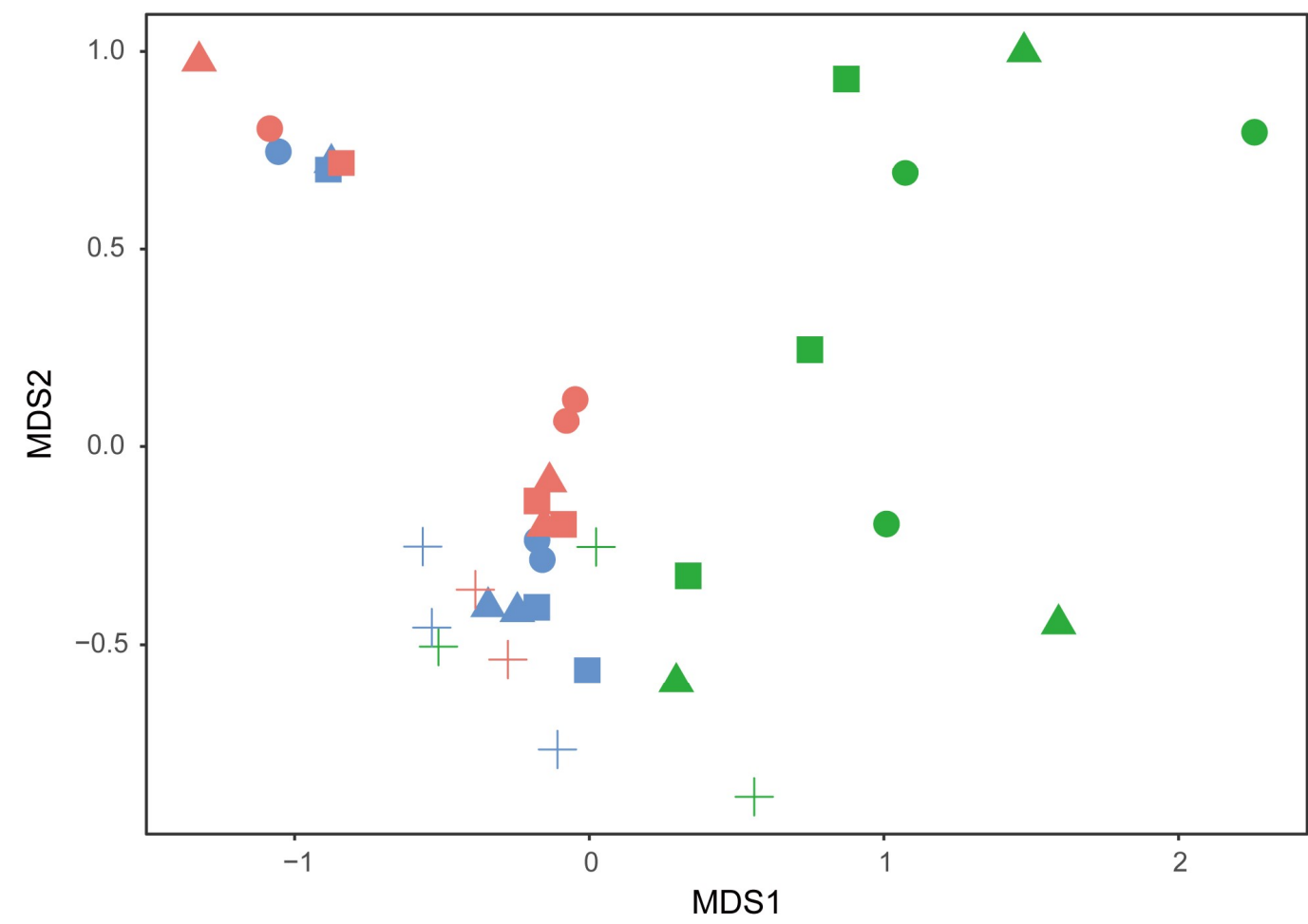

Communities

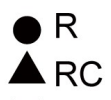

RM

$+\mathrm{T}$

Soil

Control

- MCC

- $\mathrm{HCC}$

Figure 3. Impacts of long term soil $\mathrm{Cu}$ contamination on the taxonomic compositions of transconjugal pools and corresponding recipient communities as revealed by nonmetric 2dimensional scaling analysis (NMDS). Abbreviations used: T, transconjugant pools; RM, recipient community filter mating with E. coli donor containing the pKJK5 plasmid; RC, recipient community from filter mating with $E$. coli donor without plasmid; R, recipient community from filter mating with only recipient community present; Control, low-Cu control soil; MCC, moderately contaminated soil; HCC, highly contaminated soil. Ordination is based on Weighted Unifrac distances. 


\section{Figure 4}

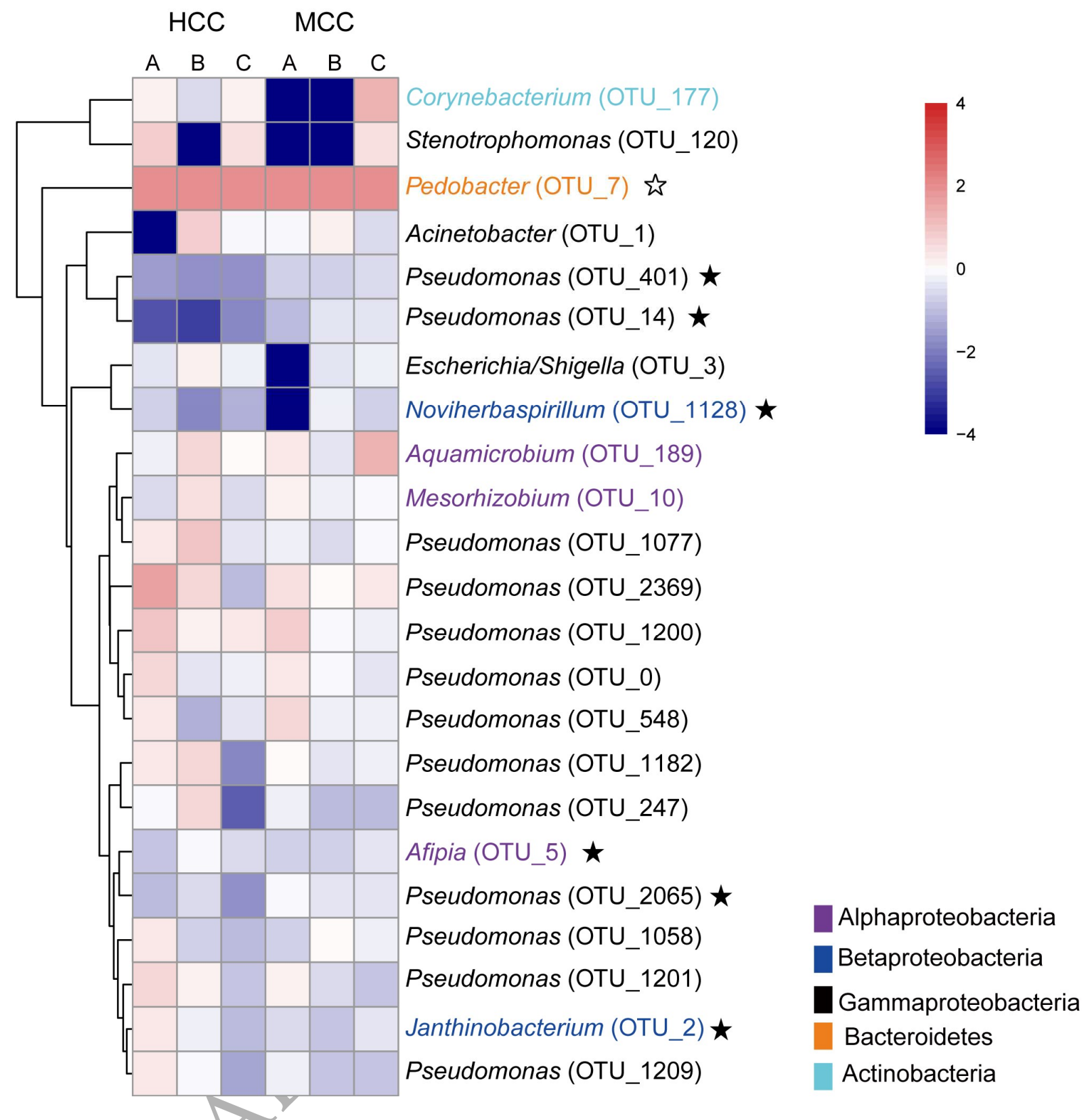

Figure 4. Heatmap clustering of the 23 operational taxonomic units (OTUs) shared between all recipient communities with an average relative abundance above $0.01 \%$ across all transconjugant pools. Clustering was performed based on similarity in how their individual permissiveness (log $\delta$ value) was altered across the copper gradient using the Bray-Curtis similarity metric. Increased permissiveness relative to low-Cu control soil is shown in red and decreased permissiveness is 
shown in blue. The 23 OTUs belonged to 5 different phyla as indicated by color coding. MCC, moderately $\mathrm{Cu}$ contaminated soil; $\mathrm{HCC}$, highly $\mathrm{Cu}$ contaminated soil. A, B, and $\mathrm{C}$ are biological replicates. Solid stars indicate OTUs with more than 2-fold decreased individual permissiveness in either MCC or HCC soils. The empty star indicates that OTU 7 was only permissive in HCC and MCC soils and the $\log \delta$ value for OTU 7 was consequently set to the highest possible value. 